\title{
Right-to-left interatrial shunting with normal right ventricular pressure A puzzling haemodynamic picture associated with some rare congenital malformations of the right ventricle and tricuspid valve
}

\author{
S. G. Haworth, E. A. Shinebourne, and G. A. H. Miller \\ From the Brompton Hospital, Fulham Road, London
}

Haemodynamic and angiographic findings are described in 5 cases with rare anomalies of the right ventricle and tricuspid valve in whom right-to-left interatrial shunting occurred in the absence of right ventricular hypertension or tricuspid atresia. In 2 cases there was congenital dysplasia of the tricuspid valve; in the first of these, this was associated with Uhl's anomaly of the right ventricle and pulmonary atresia while in the second there was isolated congenital 'absence' of the tricuspid valve. The remaining 3 cases all had isolated congenital hypoplasia of the right ventricle; in 2 of these 3 cases closure of the atrial septal defect was successful in abolishing cyanosis and symptoms, while the third is awaiting surgical correction. ${ }^{1}$

Infants and children with congenital heart disease frequently present with systemic arterial desaturation and pulmonary oligaemia due to a right-toleft shunt. Such patients usually have right ventricular outflow obstruction (pulmonary stenosis or atresia) or inflow obstruction (tricuspid atresia). In the first instance, right ventricular pressure is found to be high and, in the second, the right ventricle cannot be entered at catheterization. On rare occasions we have encountered patients presenting with cyanosis and pulmonary oligaemia in whom the right ventricle is entered at catheterization and its systolic pressure found to be normal. Such findings in combination with right-to-left interatrial shunting can be puzzling. In 5 instances in our experience, this combination of findings was caused by one or other of three rare malformations of the right ventricle or tricuspid valve - Uhl's anomaly, congenital dysplasia of the tricuspid valve, and congenital isolated hypoplasia of the right ventricle. Right-to-left interatrial shunting in such patients is presumably caused by impaired filling of the right ventricle or by tricuspid incompetence.

Received 4 July 1974.

1 Case 3 has now had successful closure of ASD.

\section{Case summaries}

Group I: Uhl's anomaly and congenital dysplasia of tricuspid valve

Case I This male infant cyanosed from birth, had a pansystolic murmur, grade $4 / 6$, at the left sternal edge, a single second heart sound, and hepatomegaly. Chest $x$-ray revealed gross cardiac enlargement with reduced pulmonary vascular markings. Echocardiography demonstrated an enormous right ventricular cavity with a large tricuspid valve orifice. His electrocardiogram showed right bundle-branch block with a $4 \mathrm{~mm}$ secondary $\mathbf{R}$ wave in VI. Cardiac catheterization and angiocardiography (Fig. I) on the first day of life revealed a dilated, poorly contracting right ventricle, generating a systolic pressure of $2 \mathrm{ImmHg}(2.8 \mathrm{kPa})$. There was gross tricuspid regurgitation. Right-to-left shunting at atrial level gave an arterial oxygen saturation of 30 per cent. The pulmonary artery could not be entered.

The baby died on the fourth day of life. At necropsy, the heart almost filled the thoracic cage. This was because of enormous dilatation of the right atrium and ventricle, the free wall of the latter being I $\mathrm{mm}$ thick (normal $=3.19 \mathrm{~mm}$, de la Cruz et al., 1960). The tricuspid orifice was greatly dilated and was $8 \mathrm{~cm}$ in diameter (normal $=35 \mathrm{~mm}$, de la Cruz et al., 1960). The valve cusps were thickened, gelatinous, and deformed, 


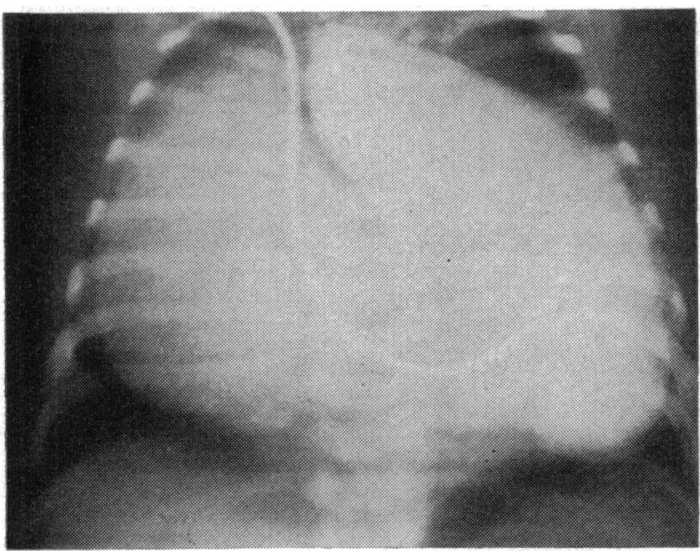

FIG. I Case I. Uhl's anomaly. Pulmonary atresia and dysplasia of tricuspid valve. Right ventricular angiogram showing a dilated right atrium and ventricle with gross tricuspid regurgitation.

but three commissures were present. The septal cusp was tethered by short chordae tendineae. Pulmonary valve atresia was present; the ventricular septum was intact. The foramen ovale was widely patent, measuring $2 \mathrm{~cm}$ in diameter, and the ductus arteriosus was $2 \mathrm{~mm}$ patent. Microscopical examination revealed a pronounced deficiency of myocardium in the right ventricular free wall, particularly in the posteroinferior wall where endocardium and epicardium were apposed in places (Fig. 2).

Case 2 This male child presented with cyanosis at 7 years of age when physical examination revealed a soft apical systolic murmur. His haemoglobin was $17.5 \mathrm{~g} / \mathrm{dl}$. The chest $x$-ray showed moderate cardiac enlargement and a reduction in pulmonary vascular markings. His electrocardiogram showed complete heart block and a

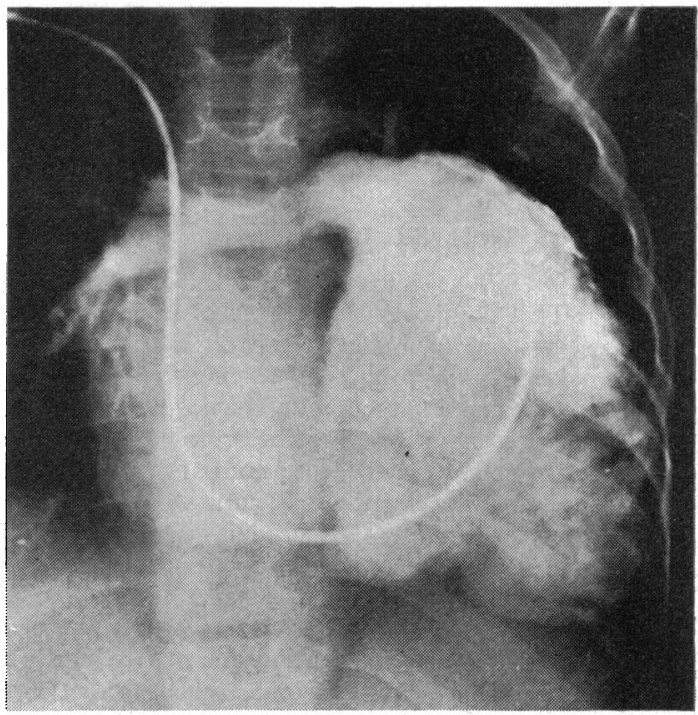

FIG. 3 Case 2. Congenital 'absence' of the tricuspid valve. Right ventricular angiogram showing a grossly dilated right ventricle and tricuspid regurgitation.

reduction in right ventricular forces, such that the $R$ waves in $V_{4} R$ and $V_{I}$ were above the roth percentile but well below the mean for his age (Namin and Miller, 1966).

At cardiac catheterization, the right ventricular pressure was $24 / 9 \mathrm{mmHg}(3.2 / 1.2 \mathrm{kPa})$. There was no gradient across the outflow tract, and though the mean right atrial pressure exceeded that of the left, no shunting was demonstrated at catheterization. Right ventricular angiography showed a very dilated right ventricle in which the outflow tract contracted more vigorously than the sinus portion. Severe tricuspid regurgitation was demonstrated (Fig. 3).

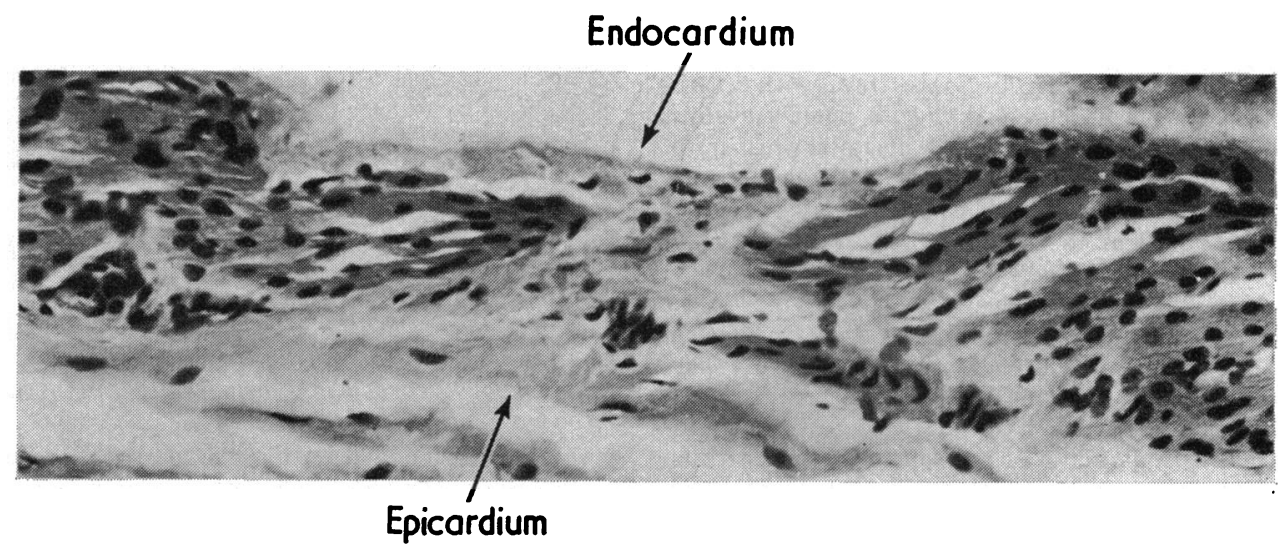

FIG. 2 Case I. Photomicrograph of a section from the free wall of the right ventricle showing (between arrows) absence of myocardial fibres between endo- and epicardium. 
The child died suddenly aged 7 years 6 months, and, at necropsy, the tricuspid valve was found to be functionally absent, being represented by three bands of thickened and fibrotic endocardium. The right atrium and ventricle were grossly dilated but the right ventricular free wall was not diminished in thickness.

\section{Group 2: Isolated hypoplasia of the right ventricle}

Case 3 This child was the second of dizygous twins. He was cyanosed from birth, had no murmurs, and a single second heart sound. At 6 months chest $x$-ray showed no cardiac enlargement and a diminution in pulmonary vascular markings. Electrocardiogram showed an axis of $+150^{\circ}$ but was otherwise normal for age.

At cardiac catheterization the right ventricular pressure was $13 / 2 \mathrm{mmHg}(1.7 / 0.3 \mathrm{kPa})$. The mean right atrial pressure exceeded that of the left and right-to-left interatrial shunting produced a systemic arterial oxygen saturation of 80 per cent. There was a presystolic pressure wave of $6 \mathrm{~mm}$ in both the right ventricle and pulmonary arterial pressure tracings, equal to the right atrial ' $a$ ' wave. Angiography demonstrated a small, smooth walled right ventricle with no outflow tract obstruction (Fig. 4). The inflow portion (sinus) was hypoplastic. The final diagnosis was congenital isolated hypoplasia of the right ventricle. He is now 5 years old, and on the 5oth percentile for height and weight. During the past three years he has become clubbed, more cyanosed, and polycythaemic, and in view of the increasing symptomatology, was recatheterized. At the second study, the findings were unchanged. Flow of contrast through the pulmonary circulation was slow and opacification of the left heart had not occurred seven seconds after injection.

Case 4 This female child was cyanosed from birth. A soft (grade 2/6) systolic murmur was first documented at Io months of age and the second heart sound was single. Her chest $x$-ray showed slight cardiac enlargement and diminution of pulmonary vascular markings. Electrocardiogram showed an axis of $+100^{\circ}$ with a I $\mathrm{mm} R$ in $\mathrm{V}_{4} \mathrm{R}$ indicating a paucity of right ventricular forces.

Catheterization at 2 years of age revealed a grossly abnormal right ventricular pressure trace with a presystolic wave of $8 \mathrm{mmHg}$ (I.I kPa), a narrow systolic spike of $14 \mathrm{mmHg}(1.9 \mathrm{kPa})$, and a diastolic pressure of $3 \mathrm{mmHg}(0.4 \mathrm{kPa})$. The presystolic wave was transmitted to the pulmonary artery where the pressure trace was almost identical to that recorded from the right ventricle. Right-to-left interatrial shunting produced a systemic arterial oxygen saturation of 8I per cent. Angiographic findings were similar to those in the last case, with a small, smooth-walled right ventricle apparently lacking a sinus portion (Fig. 5). Left ventricular angiography was normal. The final diagnosis was congenital isolated hypoplasia of the right ventricle with an atrial septal defect. Aged 6 years, she was on the roth percentile for height and weight, but had become more cyanosed with marked clubbing, and the haemoglobin had risen to $19.8 \mathrm{~g} / \mathrm{dl}$. In view of the increasing symptomatology, she was recatheterized, when the findings were

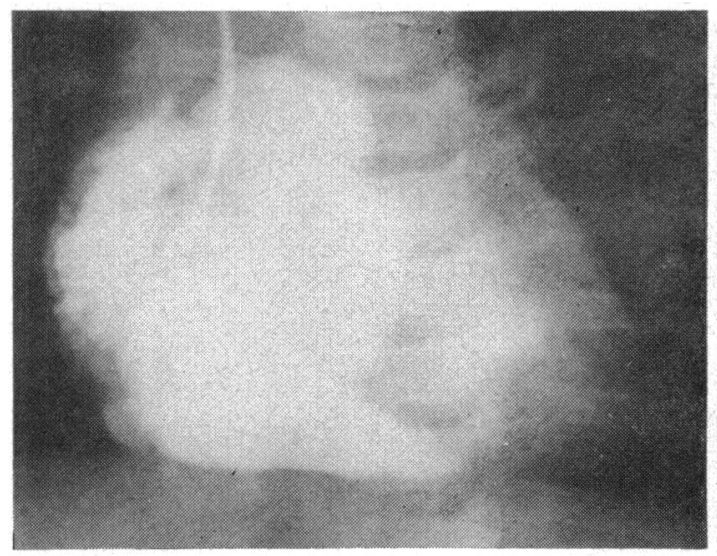

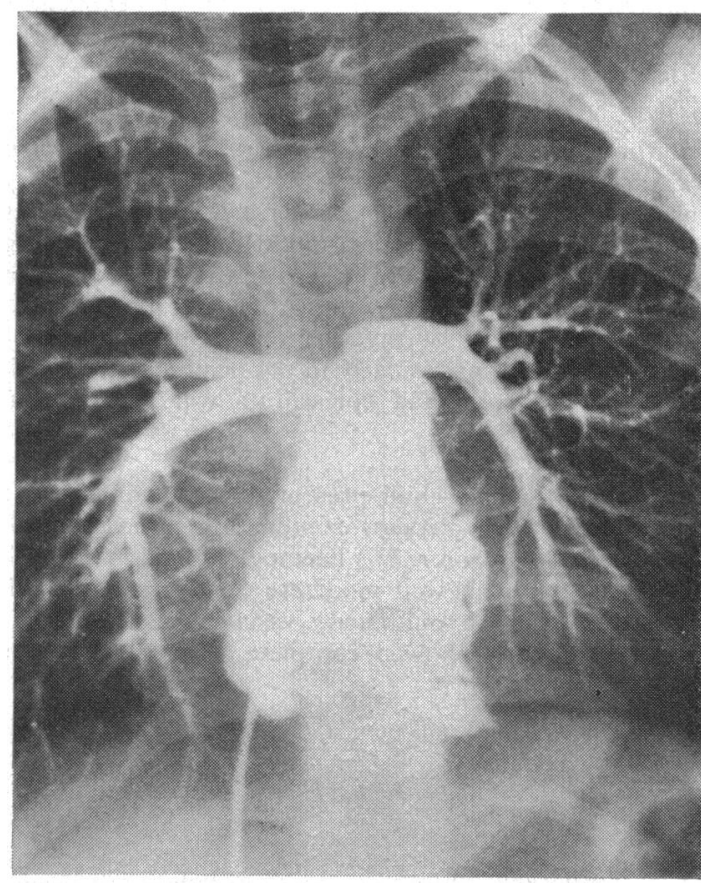

$b$

FIG. 4 Case 3. a). Isolated hypoplasia of the right ventricle. Right atrial angiogram showing small, smooth-walled right ventricle with hypoplastic sinus portion. Right-to-left interatrial shunting. b). Second study aged 5 years. Right ventricular angiogram.

essentially unchanged. Attempts to assess the effect of occluding the foramen ovale with a balloon catheter were frustrated by the onset of bradycardia and electrocardiographic ST changes.

Closure of the atrial septal defect (Mr. M. Paneth) was performed uneventfully. Apart from ventricular extra- 


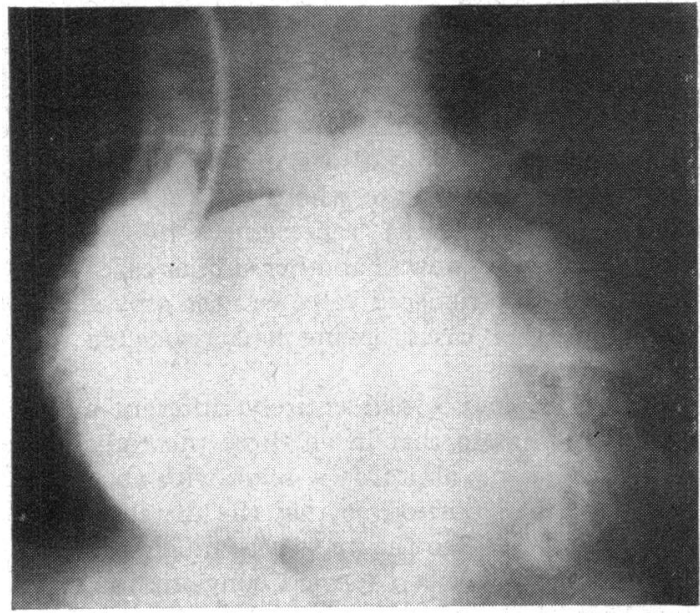

FIG. 5 Case 4. Isolated hypoplasia of right ventricle. Right atrial angiogram. Small, smooth-walled right ventricle with an extremely small sinus portion. Rightto-left interatrial shunting with opacification of left atrium.

systoles for the first three days after operation, she has remained asymptomatic.

Case 5 This 6-year-old boy was referred from overseas. He was not accompanied by a relative and no history was available. There was severe cyanosis and clubbing of the fingers and toes. There was a soft (grade r/6) ejection systolic murmur at the left sternal edge. The second heart sound was single. His haemoglobin was $25.0 \mathrm{~g} / \mathrm{dl}$. Chest $x$-ray showed slight cardiac enlargement, a small pulmonary artery, and pulmonary oligaemia, and an appearance suggesting a collateral systemicto-pulmonary arterial supply. The aorta was slightly larger than normal. The electrocardiogram showed a superior axis of $-45^{\circ}$, and $5 \mathrm{~mm} P$ waves in lead II indicating right atrial hypertrophy, but was otherwise normal. The clinical diagnosis was tricuspid atresia, but at cardiac catheterization the right ventricle was entered from the right atrium. RV pressure was $16 / 6 \mathrm{mmHg}$ $(2.1 / 0.8 \mathrm{kPa})$ with a presystolic wave of $10 \mathrm{mmHg}$ (I.3 kPa) and an abnormally narrow systolic 'spike' (Fig. 6). Right-to-left interatrial shunting resulted in an arterial saturation of 66 per cent. Attempts to occlude the atrial septal defect with a balloon catheter were unsuccessful as even an $8 \mathrm{ml}$ balloon passed freely across the septal defect. Right ventricular angiocardiography demonstrated a hypoplastic right ventricle with absent sinus portion (Fig. 7). There was no significant tricuspid incompetence.

At operation (Mr. S. C. Lennox) the atrial septum was found to be virtually absent. The tricuspid valve was perhaps slightly small, but was otherwise normal. It was difficult to define the external surface of the right ventricle. The atrial septal defect was reconstructed using a large 'dacron' patch. Postoperative progress was complicated by a sinus bradycardia for which he initially
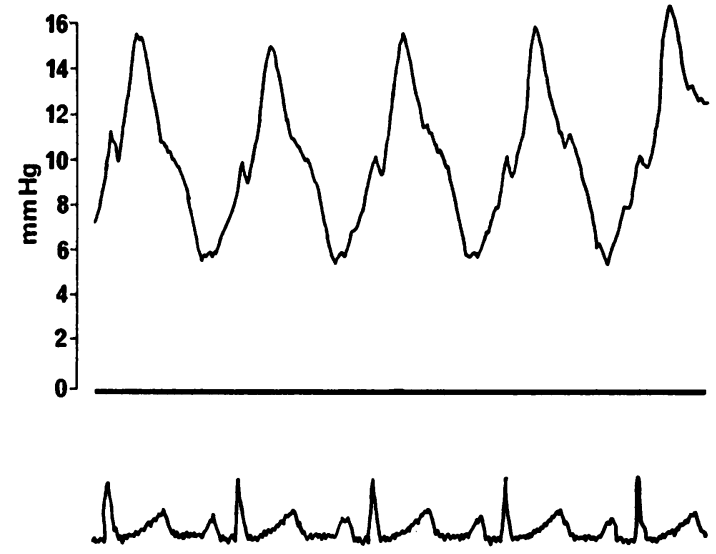

FIG. 6 Case 5. Isolated hypoplasia of right ventricle. Abnormal right ventricular pressure trace with narrow systolic 'spike' and Io $\mathrm{mm}$ presystolic wave.

required an isoprenaline drip. He was discharged well and acyanotic after three months.

\section{Discussion}

At cardiac catheterization a normal right ventricular pressure in the presence of right-to-left interatrial shunting is a surprising finding and suggests that impaired right ventricular function is causing obstruction to flow, in the absence of overt anatomical obstruction (Somerville, 1958). The differential

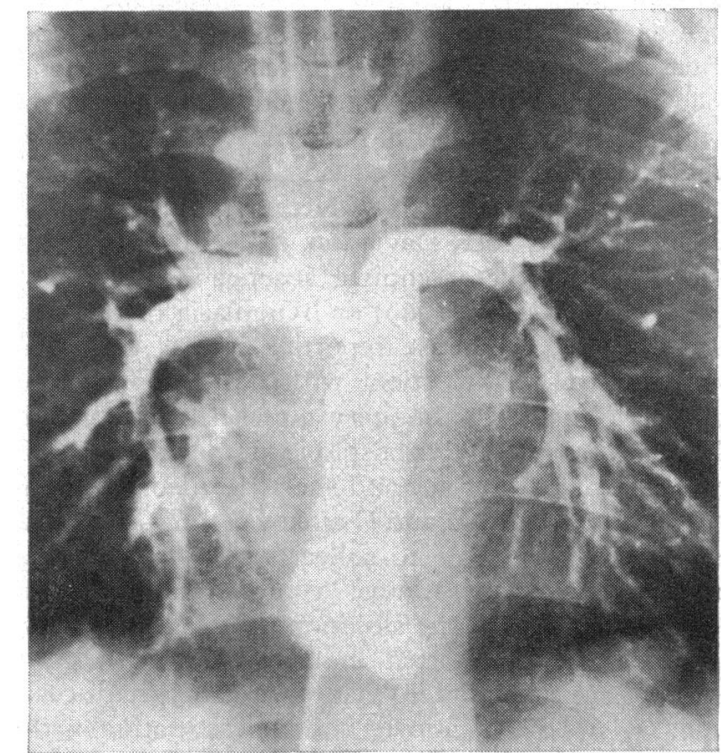

FIG. 7 Case 5. Right ventricular angiogram. Small, smooth-walled right ventricle with hypoplastic sinus portion. 
diagnosis thus includes Ebstein's malformation of the tricuspid valve, systemic disease associated with myocardial involvement (e.g. glycogen storage disease), and viral or idiopathic myocarditis. Ebstein's malformation of the tricuspid valve is probably the commonest lesion to behave in this way and was considered among the differential diagnoses in the first two patients in whom there was gross dilatation of the right ventricle. In neither of these cases, however, was there evidence of leftward displacement of the tricuspid valve either on inspection of the angiograms or at necropsy. In these two cases, therefore, dilatation of the right ventricle was assumed to be caused either by a volume load resulting from gross tricuspid incompetence or to a primary abnormality of right ventricular myocardium, or both.

Case $I$ is a special case in that this was the only patient with obstruction to right ventricular outflow since pulmonary atresia was demonstrated at necropsy. This patient might be regarded as an extreme example of pulmonary atresia with intact ventricular septum and large right ventricle - Type II (Greenwold et al., 1956). However, we have never before met with a case of pulmonary atresia in whom right ventricular pressure was normal, and this together with right-to-left interatrial shunting suggested that there was a primary abnormality of the right ventricle. This was confirmed at necropsy when pronounced deficiency of right ventricular myocardium was demonstrated - Uhl's anomaly - as well as an abnormal and undoubtedly incompetent tricuspid valve with thickened leaflets and abnormally short chordae to the septal leaflet. Patients with a combination of Uhl's anomaly and pulmonary atresia have been reported on five previous occasions (Abella et al., 1969; Neimann, Pernot, and Rauber, 1965; Côté, Davignon, and Fouron, 1973), and all had either complete absence (Côté et al., 1973; Abella et al., 1969) or hypoplasia of the tricuspid valve. The case reported here is thus the sixth example of a patient with Uhl's anomaly in conjunction with pulmonary atresia and tricuspid dysplasia. Congenital tricuspid incompetence caused by deficient valve tissue and short chordae is itself a rare condition; Antia and Osunkoya (1969) reported a case and were able to collect 13 cases from the published reports. Almost complete absence of valve tissue, as was the situation in Case 2 reported here, has been reported in association with pulmonary atresia and Uhl's anomaly on three occasions as described above, and in association with pulmonary atresia and a small right ventricle on two occasions (Klein, 1938; Kanjuh et al., 1964). In Klein's case, the tricuspid valve was represented by rudimentary vestiges of valve tissue, while in those reported by Kanjuh and co-workers there was no vestige of valve tissue. These latter authors coined the phrase 'congenitally unguarded tricuspid orifice' to avoid confusion with tricuspid atresia. Use of this term would also avoid the difficulty of nomenclature in our case where the valve, though effectively absent, was represented by residual tissue. We do not know of another similar case where 'absence' of the tricuspid valve was the only abnormality, all other cases having had associated pulmonary atresia.

Cases 3, 4, and 5 had entirely different angiographic findings in that in all three the right ventricular cavity was abnormally small with an underdeveloped sinus portion so that the distance from the tricuspid valve to the apex was much reduced. This anomaly has been termed congenital isolated hypoplasia of the right ventricle by Gasul and coworkers (1959) who provided the first detailed description of a case. These authors described abnormal right ventricular pressure traces which have a narrow systolic 'spike' and exhibit transmission of the right atrial ' $a$ ' wave to right ventricle and pulmonary artery. We observed an identical pressure trace in Case 4 so that it was impossible on manometric grounds to distinguish between pulmonary artery, right ventricle, and right atrium. In Cases 3 and 5 the right ventricular pressure trace was more normal, but still exhibited transmission of a large right atrial ' $a$ ' wave. Such abnormalities of right ventricular and pulmonary arterial pressure traces are not unique to this condition, however, having been described in cases of Uhl's anomaly (Cumming, Bowman, and Whytehead, 1965) and Ebstein's disease (Blount, McCord, and Gelb, 1957).

Isolated hypoplasia of the right ventricle has been reported on I5 occasions (Gasul et al., 1959; Sackner et al., 196I ; Medd et al., 196I ; Enthoven, Dunst, and Richman, 1963; Fay and Lynn, 1963; Stoermer and Apitz, 1965; Raghib et al., 1965; Davachi et al., 1967; Hollman, 1968; Okin et al., 1969; Van der Hauwaert and Michaelsson, 1971) and our Cases 3 and 4 have previously been reported elsewhere (Vassallo, 1971).

Gradual deterioration with increasing cyanosis has been a feature of our cases as well as others previously reported. Closure of the foramen ovale has been reported as abolishing clinical symptoms (Van der Hauwaert and Michaelsson, 1971), though it has been suggested that the selection of suitable cases depends on identifying a right ventricle capable of handling an increased flow (Van Der Hauwaert and Michaelsson, 1971 ; Hollman, 1968). The effect of closing the atrial defect can be tested at cardiac catheterization by inflating a balloon-tipped catheter in the defect (Van Der Hauwaert and Michael- 
sson, 1971), though this procedure may be complicated by conduction disturbances, to which these patients are susceptible (Van der Hauwaert and Michaelsson, 1971 ; Sackner et al., I96I ; Medd et al., 196r ; Davachi et al., 1967). Attempts to occlude the atrial septal defect by balloon catheter were unsuccessful in the two cases in whom we attempted this procedure. Surgical closure of the atrial septal defect in Cases 4 and 5 reported here was very successful though in Case 5 convalescence was prolonged by a tendency to sinus bradycardia, suggesting that the right ventricle did have difficulty in adapting to the increased flow resulting from abolition of the rightto-left shunt. Our remaining case of isolated hypoplasia of the right ventricle is awaiting surgical correction.

An alternative surgical approach is to increase pulmonary blood flow by creating an aorto-pulmonary anastomosis, and a Glenn procedure has been helpful in some children with hypoplastic right ventricle (Gasul et al., 1959; Enthoven et al., 1963; Fay and Lynn, 1963). Though the aetiology of the condition is unknown, a familial incidence has been reported (Medd et al., 196r ; Sackner et al., 196r ; Raghib et al., 1965; Davachi et al., 1967).

Although the diagnosis of isolated hypoplasia of the right ventricle can be made by angiography, the angiographic demonstration of a dilated and poorly contracting right ventricle in association with a normal right ventricular pressure and right-to-left interatrial shunting, still leaves a number of diagnostic possibilities. Cases I and 2 described here are examples of rare congenital malformations which can present in this way; in our experience, an identical picture may be seen in infants with 'idiopathic myocarditis' and we have experience of two neonates who presented in this way. In one, death occurred at 4 days of age and myocarditis was demonstrated histologically, while in the other spontaneous recovery suggested a similar aetiology.

We wish to thank Dr. R. V. Gibson and Dr. Michael Joseph for permission to publish details of patients admitted under their care.

\section{References}

Abella, J. B., Van Praagh, R., Novak, G., Miller, R. A., and Hastreiter, A. R. (1969). Congenital absence of tricuspid valve leaflets. American fournal of Cardiology, 23, 104.

Antia, A. U., and Osunkoya, B. O. (1969). Congenital tricuspid incompetence. British Heart fournal, 31, 664.

Blount, S. G., McCord, M. C., and Gelb, I. J. (1957). Ebstein's anomaly. Circulation, 15, 2 ro.

Côté, M., Davignon, A., and Fouron, J. C. (1973). Congenital hypoplasia of right ventricular myocardium (Uhl's anomaly) associated with pulmonary atresia in a newborn. American fournal of Cardiology, 31, 658.

Cumming, G. R., Bowman, J. M., and Whytehead, L. (1965). Congenital aplasia of the myocardium of the right ventricle (Uhl's anomaly). American Heart fournal, 70, 671.
Davachi, F., McLean, R. H., Moller, J. H., and Edwards, J. E. (1967). Hypoplasia of the right ventricle and tricuspid valve in siblings. Fournal of Pediatrics, 71, 869.

De la Cruz, M. V., Anselmi, G., Romero, A., and Monroy, G. (1960). A qualitative and quantitative study of the ventricles and great vessels of normal children. American Heart fournal, 60, 675.

Enthoven, R., Dunst, M., and Richman, B. (1963). Congenital hypoplasia of the right ventricle and tricuspid valve with survival into adult life. American fournal of Cardiology, II, 532.

Fay, J. E., and Lynn, R. B. (1963). Isolated right ventricular hypoplasia with atrial septal defect. Canadian Medical Association fournal, 88, 812.

Gasul, B. M., Weinberg, M., Luan, L. L., Fell, E. H., Bicoff, J., and Steiger, Z. (1959). Superior vena cava right main pulmonary artery anastomosis: surgical correction for patients with Ebstein's anomaly and for congenital hypoplastic right ventricle. Fournal of the American Medical Association, 171, 1797.

Greenwold, W. E., DuShane, J. W., Burchell, H. B., Bruwer, A., and Edwards, J. E. (1956). Congenital pulmonary atresia with intact ventricular septum: two anatomic types. Circulation, 14, 945.

Hollman, A. (1968). Underdevelopment of the right ventricle. In Paediatric Cardiology, p. 50r. Ed. by $\mathrm{H}$. Watson. Lloyd-Luke, London.

Kanjuh, V. I., Stevenson, J. E., Amplatz, K., and Edwards, J. E. (1964). Congenitally unguarded tricuspid orifice with co-existent pulmonary atresia. Circulation, 30, 91 r.

Klein, H. (1938). Uber einen seltenen Fall von Herzmissbildung mit rudimentärer Entwicklung des rechten Ventrikels und Defeckt der Tricuspidalklappen. Virchow's Archiv für pathologische Anatomie und Physiologie, 301, I.

Medd, W. E. Neufeld, H. N., Weidman, W. H., and Edwards, J. E. (r96r). Isolated hypoplasia of the right ventricle and tricuspid valve in siblings. British Heart fournal, 23, 25.

Namin, E. P., and Miller, R. A. (1966). The normal electrocardiogram. In Electrocardiography in Infants and Children, p. IO2. Ed. by D. E. Cassells and R. F. Ziegler. Heineman Medical Books, London.

Neimann, N., Pernot, C., and Rauber, G. (1965). Aplasie du myocarde du ventricule droit (ventricule droit papyracé congénitale). Archives des Maladies du Coeur et des Vaisseaux, 58, 421 .

Okin, J. T., Vogel, J. H. K., Pryor, R., and Blount, S. G. (1969). Isolated right ventricular hypoplasia. American fournal of Cardiology, 24, 135.

Raghib, G., Amplatz, K., Moller, J. H., Jue, K. L., and Edwards, J. E. (1965). Hypoplasia of right ventricle and of tricuspid valve. American Heart fournal, 70, 806.

Sackner, M. A., Robinson, M. J., Jamison, W. L., and Lewis, D. H. (I96I). Isolated right ventricular hypoplasia with atrial septal defect or patent foramen ovale. Circulation, 24, 1388.

Somerville, W. (1958). Atrial septal defect: reversed shunt with normal pulmonary vascular resistance. British Heart fournal, 20, 265.

Stoermer, J., and Apitz, J. (1965). Der Sogenannte isolierte hypoplastische rechte Ventrikel mit Vorhofseptumdefekt oder offenem Foramen ovale. Medizinische Klinik, 60, 1777 .

Van der Hauwaert, L. G., and Michaelsson, M. (I971). Isolated right ventricular hypoplasia. Circulation, 44, 466.

Vassallo, Agius P. (197I). Isolated right ventricular hypoplasia with atrial septal defect. St. Luke's Hospital Gazette, Malta, 6, 36.

Requests for reprints to Dr. G. A. H. Miller, Brompton Hospital, Fulham Road, London $\mathrm{SW}_{3} 6 \mathrm{HP}$. 